\title{
Role of Private Sector in Advancing Neurosciences in Africa: Memfys Hospital Example
}

\author{
Samuel C Ohaegbulam* \\ Memfys Hospital, Enugu, Nigeria
}

*Corresponding author: Samuel C Ohaegbulam, Memfys Hospital, Enugu, Nigeria.

Received Date: January 29, 2020

Published Date: February 10, 2020

\begin{abstract}
s
Neurosurgery in Africa had depended on the Public health services for growth but sadly after over half a century, progress has been disappointing. This paper advocates an alternative approach. Memfys Hospital was established in 2002 as a pioneering private sector effort in this direction and the results suggest that this might be a better route to follow.
\end{abstract}

\section{Method}

Although neuroscience originated in ancient Egypt, its transformation into modern neurosurgery took place outside Africa. Modern neurosurgery in Africa coincidentally also started from Egypt in 1951 when Osman Sorour founded the Department of Neurosurgery at Cairo University. Professor Sorour later became the foundation president of the Pan African Association of Neurological Sciences (PAANS) which over the years gave birth to other neurological and neurosurgical associations in Africa. In SubSaharan Africa, neurosurgery probably started in Rhodesia (now Zimbabwe) in 1956 and in West Africa, it was started in Nigeria in 1962.

The main challenges facing neurosurgery in Africa are workforce development and funding [1,2]. When compared to the other continents, Africa is still far behind despite efforts to improve on these statistics [3,4]. The contributions of neurosurgeons from many countries in Africa, Europe, Asia and USA are helping us train more neurosurgeons. International bodies like WFNS, FIENS, ENS, AANS, CNS and Japanese Neurosurgery Society, to mention a few, have demonstrated exceptional understanding of the situation and have consistently provided their assistance and support. African neurosurgery is trying to metamorphose into a multispecialty service. For most neurosurgeons in Africa, such a transformation is premature. But for some countries like Egypt, Algeria, South Africa and Morocco that have achieved respectable numbers, the subspecialization is understandable hence it is on the increase. No one can be sure of what is best for Africa but for many years to come, we must continue to produce general neurosurgeons that are able to manage most problems confronting them in their daily practices.

African neurosurgeons always lament that they have virtually nothing to work with. Sadly, African governments prefer to invest disproportionate amount of scarce resources on defense necessitated by security concerns. Public Health consumes a lion share of what is available for Health services. Universal Health Insurance has not yet progressed to improve on healthcare financing There is therefore the need for alternative solutions including the establishment of neurosurgery services outside the public hospitals.

Role of private sector: Memfys Hospital Enugu Nigeria (MHN)

Memfys hospital for Neurosurgery was established to fill the gap created by deficiencies in the Public healthcare system in Nigeria. The founder of MHN returned to Nigeria after his training in Britain and pioneered neurosurgery service at the University of Nigeria. After about twenty years of struggling to deliver service with inadequate facilities, he opted to prematurely retire from public 
service to start the first private neurosurgical hospital in West Africa. From its humble beginnings, the hospital has now grown to become one of the important Tertiary Institutions in Nigeria and the only private hospital with full accreditation for postgraduate training of doctors by the West African College of Surgeons and the Nigeria Postgraduate Medical College (Table 1)

Table 1: Patient Volume.

\begin{tabular}{|c|c|c|c|c|}
\hline \multicolumn{5}{|c|}{ MHN Services 2002-2019 } \\
\hline New Clinic Patients & CT Scans & MRI Scans & Admissions & Operations \\
\hline 27950 & 15,189 & 17,096 & 4164 & 3265 \\
\hline
\end{tabular}

\section{Contributions of MHN}

MHN has provided Research facilities for thesis and dissertations for MSc. and PhD programmes for some Universities. The hospital has also participated and sponsored numerous publications in Academic Journals and has hosted conferences and workshops. Modern facilities are scarce in African hospitals but Memfys has over the years invested substantial resources to achieve an international standard. The Radiology department with 0.35T and 1.5T MRI machines, a 64-Slice and 8-Slice CT scanners, 4D Doppler US, Digital X-Ray machine as well as C-Arms is the best equipped in South East Nigeria and one of the best in West Africa. The two Operating Suites have all facilities for complex brain and Spine surgeries including the first Zeiss Pentero 900 Microscope in West Africa

\section{Training and Education}

In 2002 when the hospital started, there was no neuroscience training center in South East Nigeria. There were only 10 Neurosurgeons in the entire country for a population of about 140 million. The unacceptable scarcity of neuroscientists in Africa and

Table 2: Trainees MHN. other Developing nations has been of concern to the International community. The WHO recommends one neurosurgeon per 100,000 population. However, it is now believed that sub-specialization has rendered that estimate inadequate [5] but Nigeria currently estimated to be 200 million population, has one neurosurgeon per 2.4 million population. The WFNS has agonized over this problem hence the "Africa 100" initiative by a Past President of WFNS (Magid Sami) who pledged his personal resources to train 100 neurosurgeons for Africa within a short period of time.

Although Neurosurgery was first introduced to Nigeria, progress was slow for half a century6 partly because of over reliance on Public Institutions. During those years, only two Federal Universities were engaged in neurosurgery training - University of Ibadan and University of Lagos. The establishment of Memfys Hospital added new life to the struggle to improve Neurosurgery workforce. Today, the number of neurosurgeons has increased to 82 and MHN has contributed partially or fully in training 21(25\%). Additionally, Memfys Hospital has assisted other specialties in their training efforts (Table 2).

\begin{tabular}{|c|c|c|c|c|c|}
\hline \multicolumn{5}{|c|}{ Trained Postgraduate Doctors at Memfys Hospt: } & \multirow[b]{2}{*}{$\begin{array}{c}\text { Neuroradiology (CT/ } \\
\text { MRI) }\end{array}$} \\
\hline $\begin{array}{c}\text { Neurosurgery Trainees (full } \\
\text { training) }\end{array}$ & Current NS Trainees: & $\begin{array}{l}\text { Otolaryngology } \\
\text { Trainees }\end{array}$ & $\begin{array}{l}\text { Ophthalmology } \\
\text { Trainees }\end{array}$ & $\begin{array}{l}\text { Neuro anes- } \\
\text { thesia }\end{array}$ & \\
\hline 21 & 13 & 10 & 20 & 20 & 13 \\
\hline
\end{tabular}

\section{Conclusion}

Advancing neurosurgery in Africa requires looking beyond Public institutions. Private Sector should be encouraged to participate and could make a big difference as experience in the USA has shown

\section{Acknowledgement}

None.

\section{Conflict of Interest}

No conflict of interest.

\section{References}

1. Ohaegbulam SC (2016) Sustainable funding/financing of the Health Sector in Nigeria in Towards a New Dawn for the Health Sector in Nigeria
Post 2015. In: Olusegun Obasanjo, Mabogunje AL, Okebukola PA (Eds.), Publ by Centre for Human Resources OOPL Abeokuta Nigeria, Sterling Publ Delhi, Slough UK, pp. 125-146.

2. Tyler J Kenning (2016) Neurosurgical Workforce shortage: The effect of Sub specialization and a case for shortening Residency Training. AANS Neurosurgeon 25(4).

3. Fuller A, Tran T, Muhumuza M, Haglund MM (2016) Building Neurosurgical capacity in low and middle income countries. eNeurosurgical Sci 3: 1-6.

4. Park KB, Johnson WD, Dempsey K (2016) Global neurosurgery: the unmet need. World Neurosurg 88: 32-35.

5. Barrow DL (2013) Subspecialization in Neurosurgery. World neurosurgery 80(5): e105-e106.

6. Ohaegbulam SC (2008) Half a century of neurosurgery in Nigeria. Afr J Med Med Sci 37(3): 293-302. 